Article

\title{
Shared Tuned Mass Dampers for Mitigation of Seismic Pounding
}

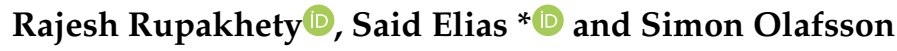 \\ Earthquake Engineering Research Centre, Faculty of Civil and Environmental Engineering, School of \\ Engineering and Natural Sciences, University of Iceland, Austurvegur 2a, 800 Selfoss, Iceland; \\ rajesh@hi.is (R.R.); simon@hi.is (S.O.) \\ * Correspondence: said@hi.is
}

Received: 17 January 2020; Accepted: 6 March 2020; Published: 11 March 2020

\begin{abstract}
This study explores the effectiveness of shared tuned mass damper (STMD) in reducing seismic pounding of adjacent buildings. The dynamics of STMDs is explored through numerical simulations of buildings idealized as single and multiple degree of freedom oscillators. An optimization method proposed in the literature is revisited. It is shown that the optimization results in two different solutions. The first one corresponds to the device being tuned to one of the buildings it is attached to. The second solution corresponds to a very stiff system where the TMD mass hardly moves. This solution, which has been described as an STMD in the literature, is shown to be impractical due to its high stiffness and use of a heavy stationary mass that plays no role in response mitigation but adds unnecessary load to the structure. Furthermore, it is shown that the second solution is equivalent to a viscous coupling of the two buildings. As for the properly tuned solution, i.e., the first solution, sharing the device with an adjacent building was found to provide no added benefits compared to when it is placed on one of the buildings. Based on results from a large set of real earthquake ground motions, it is shown that sharing a TMD mass with an adjacent building, in contrary to what is reported in the literature, is not an effective strategy.
\end{abstract}

Keywords: adjacent buildings; seismic pounding; tuned mass damper

\section{Introduction}

Seismic pounding refers to the collision of adjacent structures during earthquakes. When closely spaced structures vibrate out of phase, they might pound against each other. Pounding can cause local damage at the contact region. In addition, the impact generates short-duration acceleration pulse that can adversely affect the pounding buildings and their contents (see, for example, Abdel Raheem [1], and references therein). Such effects have been documented during past earthquakes. Miari et al. [2] and Abdel Raheem et al. [3] provide very good reviews of seismic pounding and refer to many studies describing pounding observed during past earthquakes. Various methods of modeling pounding and computation of structural response have been discussed in the literature (see, for example, Dimitrakopoulos, [4]).

Pounding can be avoided if adjacent buildings are adequately separated, but there is large uncertainty in just how much separation is adequate. Architectural and financial factors often dictate separation distance between buildings in metropolitan areas where land is expensive and scarce. Mitigation of seismic pounding is, therefore, an important structural engineering problem. One approach is to reduce the consequences of pounding, while the other is to reduce probabilities of pounding. Collision shear walls have been found to be effective in reducing the consequences of pounding (Anagnostopoulos and Karamaneas, [5]). Elastic gap devices (see, for example, Dicleli, [6]), have been shown to be effective in mitigating damage caused by pounding. 
Several solutions for reducing probabilities of pounding between adjacent structures have been proposed in the literature. These solutions range from connecting adjacent buildings with springs and viscous/viscoelastic dashpots (Jankowski and Mahmoud, [7]; Richardson et al., [8,9]; Patel and Jangid, [10,11]; and Tubaldi, [12]). Friction dampers and viscous fluid dampers have also been proposed for mitigation of pounding risk (see, for example, Pratesi et al., [13] and Sorace and Terenzi, [14]).

Active, semi-active, and fuzzy control using magneto-rheological dampers have also been shown to be effective for seismic pounding mitigation (see, for example, Abdeddaim et al., [15]; Uz and Hadi, [16]). Pounding risk may be reduced by controlling the vibrations of adjacent structures. Tuned mass dampers (TMDs) for vibration control have been extensively studied in the literature (see, for example, Cao and Li, [17] or the review by Elias and Matsagar, [18]).

The risk of pounding in base-isolated buildings is higher due to large displacements concentrated at the isolation level (Agagnostopoulos and Spiliopoulos, [19]). Controlling displacement demands on base-isolated structures has been investigated using different strategies in the literature. These strategies include the use of tuned liquid column dampers [20], and tuned mass dampers located at different locations of the host buildings [20-23]. Coupling of base isolation system with tuned mass damper inerter systems is reported in De Domenico and Ricciardi [24], Hashimoto et al. [25] and De Domenico et al. [26]. Other strategies for displacement control of base-isolated buildings include the use of gap dampers [27].

While several studies on active and semi-active dampers for pounding mitigation are available in the literature, very few have tested passive TMDs for this purpose. The only work we are aware of in this regard is that of Abdullah et al. [28]. The idea was extended to semi-active TMD by Kim [29]. Abdullah et al. [28] presented the concept of a shared TMD to reduce vibrations and seismic pounding between adjacent buildings. Their optimal solution is to connect the TMD mass with a spring to one of the buildings and with a dashpot to the other building. If effective, this device could be advantageous due to its simplicity and low cost compared to active control schemes. One of the main appeals of this scheme is that the mass of the shared TMD is only half the mass of two TMDs installed on individual buildings.

Abdullah et al. [28] reported that the device is very effective in controlling vibrations and pounding between adjacent buildings. Upon closer inspection, we find that the solution presented by Abdullah et al. [28] is neither a tuned mass damper, nor optimal in mitigating pounding, and needs revisiting. The main objective of this paper is to investigate the dynamics of adjacent buildings connected by a tuned mass damper. We use single degree of freedom (SDOF) and multiple degree of freedom (MDOF) representations of buildings and several earthquake ground motions for numerical simulations to investigate the parameters of TMDs for optimal control of structural displacements and pounding.

\section{Conceptual and Mathematical Model of Shared TMDs (STMD)}

For conceptual convenience, let us consider two single degree of freedom (SDOF) systems connected by a shared TMD as shown in Figure 1. The SDOFs are simplified representations of buildings $A$ and $B$, and their masses, stiffnesses, and damping coefficients are denoted as $m_{A}, m_{B} ; k_{A}$, $k_{B}$; and $c_{A}, c_{B}$, respectively. The mass, stiffness and damping coefficient of the tuned mass damper are denoted by $m, k$, and $c$, respectively. An alternate scheme is to connect the TMD mass to building A with a dashpot and to building $B$ with a spring. 


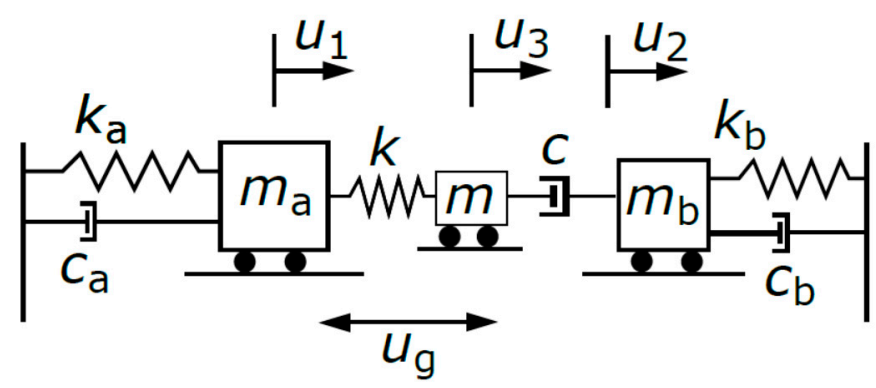

Figure 1. Schematic representation of a tuned mass damper (TMD) shared by two buildings modeled as single degree of freedom (SDOF) systems.

The system mass, stiffness, and damping matrices are given below.

$$
\begin{gathered}
\mathbf{K}=\left[\begin{array}{ccc}
k_{A}+k & 0 & -k \\
0 & k_{B} & 0 \\
-k & 0 & k
\end{array}\right] \\
\mathbf{M}=\left[\begin{array}{ccc}
m_{A} & 0 & 0 \\
0 & m_{B} & 0 \\
0 & 0 & m
\end{array}\right] \\
\mathbf{C}=\left[\begin{array}{ccc}
c_{A} & 0 & 0 \\
0 & c_{B}+c & -c \\
0 & -c & c
\end{array}\right]
\end{gathered}
$$

and the state matrix is defined as

$$
\mathbf{S}=\left[\begin{array}{cc}
0 & \mathbf{I} \\
-\mathbf{M}^{-1} \mathbf{K} & -\mathbf{M}^{-1} \mathbf{C}
\end{array}\right]
$$

where I is an identity matrix. The performance (or cost) function, as defined by Abdullah et al. (2001) is the trace of a matrix $\mathbf{L}$, which satisfies the following Lyapunov equation.

$$
\mathbf{L S}+\mathbf{S}^{\mathrm{T}} \mathbf{L}+\mathbf{Q}=0
$$

where $\mathbf{Q}$ is a weighting matrix that assigns different importance to the displacements (and/or velocities) at the different degrees of freedom of the system. The design problem is then to estimate $k$ and $c$ that minimize the trace of $\mathbf{L}$, denoted hereafter by $J$. The weighting matrix is taken as $\mathbf{Q}_{11}=1$ and all other elements as 0 .

\section{Numerical Study}

We present several numerical studies, starting with SDOF systems subjected to some example ground motions. MDOF systems and a large set of ground motions are considered next. The section starts with an example of an optimization problem to gain insight into the properties of STMDs.

\subsection{An Optimization Example}

An example of the optimization problem is presented here. The properties of buildings A and $\mathrm{B}$ are fixed for numerical simulations. Their frequencies are taken as 6.04 and $7.58 \mathrm{rad} / \mathrm{s}$, and the damping ratio is $5 \%$ for both. The frequencies are the same as those of the two buildings studied by Abdullah et al. [28]. The mass of the two buildings are equal, and the mass of the TMD is expressed as a fraction of the mass of building A, i.e., $m=\rho_{A} m_{A}$. The frequency of the TMD is denoted by $\omega=\sqrt{\frac{k}{m}}$, 
and the frequency ratio is defined as $f=\frac{\omega}{\omega_{A}}$. The damping ratio of the TMD, expressed in terms of the mass and frequency of the TMD, is denoted by $\zeta$. The variables of interest are therefore $f$ and $\zeta$.

Figure 2 shows the variation of the cost function with the frequency ratio and damping ratio of the TMD. The cost function has two minima, which correspond to two solutions. There is a local minimum near a frequency ratio of 1 . This minimum is more prominent for lower damping ratios. The global minima occur at much larger frequency ratios, ranging from about 10 to about 90 for damping ratios from 0.4 to 0.05 . It is interesting to note that the amplitudes of the global minima are not very sensitive to damping ratios of the TMD.

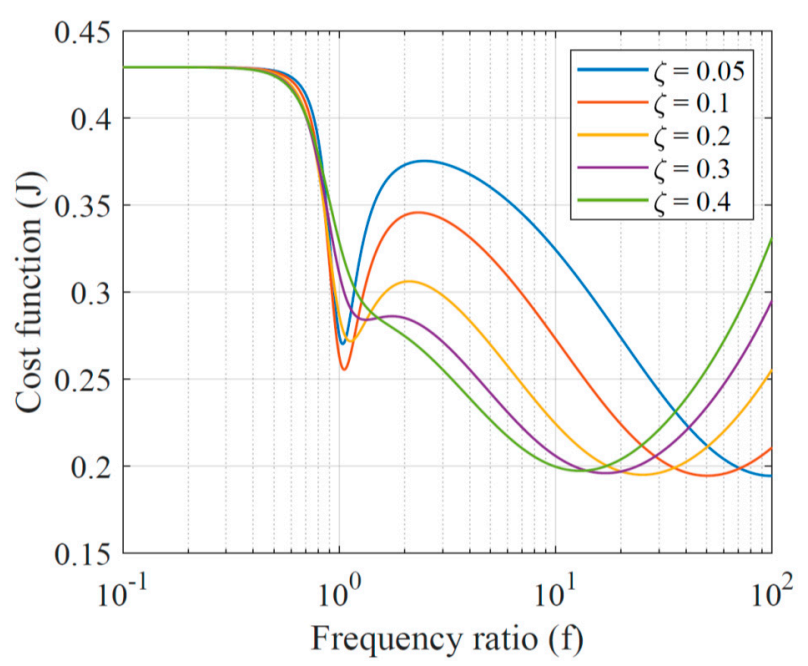

Figure 2. Variation of the cost function with frequency ratio and damping ratio of the TMD. Themass of the TMD is taken as $3 \%$ of the mass of building A in this example.

It is then interesting to investigate whether the solution that minimizes $J$ corresponds to minimum displacements of the two buildings and minimizes the separation distance required to prevent pounding. This distance is the largest negative relative displacement between the two buildings and is hereafter referred to as the pounding distance. To investigate this, we use the north-south component of the El Centro ground motion from the 1940 Imperial Valley Earthquake and simulate the response of the two buildings and STMD with varying frequency and damping ratios.

The results are shown in Figure 3. The maximum displacement of the two buildings are shown on the top panel. The maximum stroke of the TMD is shown in the bottom left panel. Here, stroke is defined as the relative displacement of the TMD mass from building A. Pounding distance is shown in the bottom right panel. For comparison, the response of uncontrolled buildings is shown with black dashed lines. Another scenario considered is where an optimally tuned (based on Sadek, [30]) TMD is placed on building A whereas building B is uncontrolled. In this case, the frequency tuning ratio is 0.96 and the damping ratio is 0.22 . The results corresponding to this are shown with dashed blue lines. The results show that the local minima, similar to those observed in Figure 2, occurs in the displacement response of building A when the TMD is tuned to the frequency of the building. However, the combination of $f$ and $\zeta$ that minimizes $J$ does not necessarily minimize the displacement of building A. For example, for $f$ approximately equal to 1, a damping ratio of $10 \%$ is required to minimize $J$, whereas $5 \%$ damping ratio minimizes the peak displacement of building $\mathrm{A}$. This can be explained by the larger stroke of the device when the damping ratio is low, as is clearly seen in the bottom right panel of Figure 3. The optimal solution near $f \approx 1$ is not effective in controlling the peak response of building $B$. 

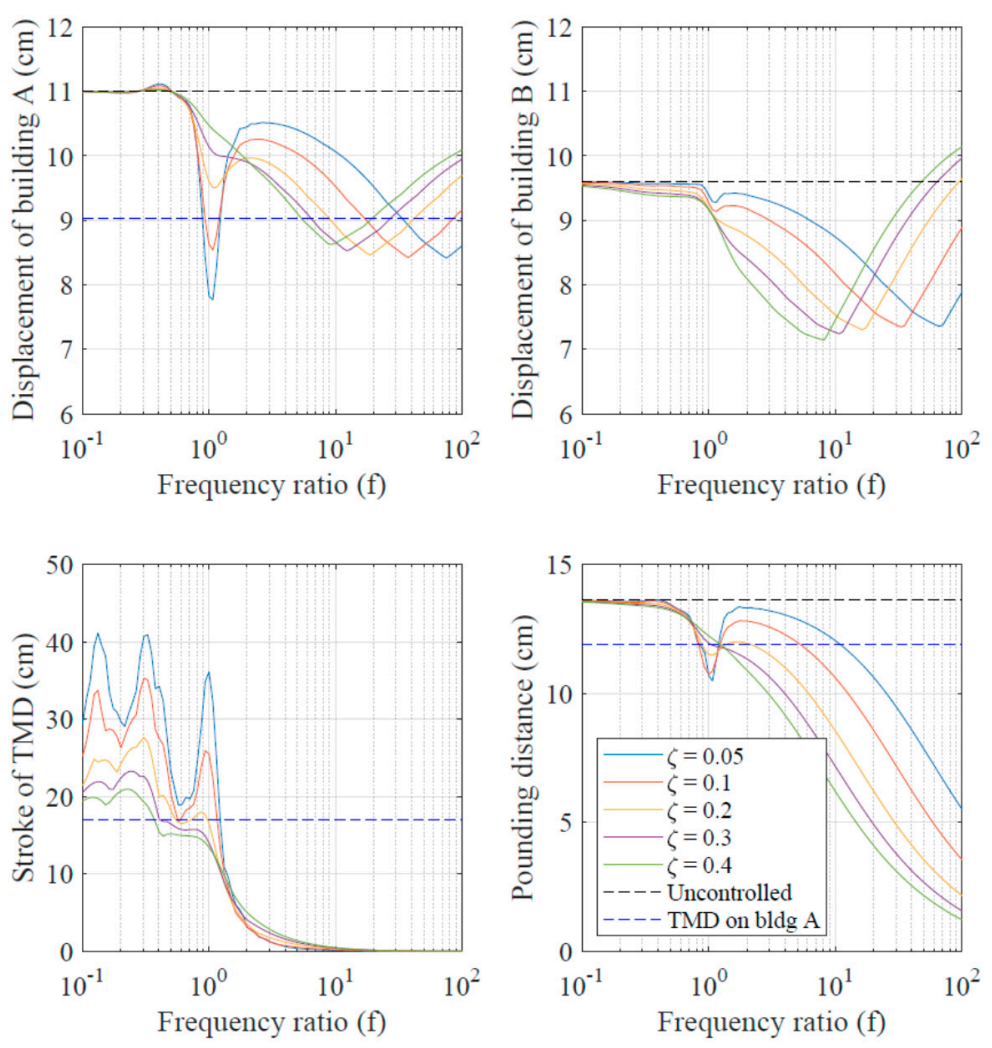

Figure 3. Peak displacement of building A, displacement of building B, stroke of the TMD, and minimum separation.

It is also interesting to note that the locally optimal solution $(f \approx 1)$ of the shared TMD is more effective in controlling peak response of building $\mathrm{A}$, and with a much smaller damping ratio than when the TMD is placed only on building A. This indicates that sharing a TMD with an adjacent building can increase its effectiveness without adversely affecting the response of the adjacent building. This, however, comes at a cost of increased stroke of the device, which is due to low damping values of the locally optimal STMD, as is evident from the bottom left panel of Figure 3. The stroke of the locally optimal STMD is much larger than the stroke of the TMD placed on building A.

As the frequency ratio is increased, the displacement response of both the buildings show a decreasing trend followed by an increasing trend. This trend is also visible in the cost function shown in Figure 2. If we consider the minima (based on the cost function) at a higher frequency ratio as the global minima, the optimal frequency ratio decreases with increasing damping, and the optimal solutions are more effective than TMD placed on building A alone. However, these optimal solutions correspond to very stiff springs in the TMD. For a damping ratio as large as $40 \%$, the optimal frequency ratio is about 10. With a mass ratio of $3 \%$, the stiffness of the TMD is about 3 times the stiffness of building A. From a practical point of view, it might not feasible to construct a TMD which is so much stiffer than the building it rests on. Such a solution, although not realistic, will be hereafter referred to as a globally optimal solution referring to the cost function.

At the locally optimal solution, the shared TMD reduces the minimum separation distance to some extent. As the frequency ratio and damping ratio are increased, the pounding distance decreases further. With a very stiff TMD and sufficiently high damping ratio, it appears the pounding distance can be reduced to a large extent. While this seems like a plausible mitigation strategy against pounding, it is deficient in both conceptual and practical terms. In practical terms, having a TMD 3 times stiffer than the building itself is not attractive. The conceptual deficiency is that such a stiff device cannot be considered as a TMD. This can be better understood by inspecting the results shown in the bottom left panel of Figure 3. Irrespective of the damping ratio, as the frequency ratio increases above 1, the 
stroke of the TMD reduces rapidly, and for a frequency ratio of 10 , the device does not move relative to building A. Therefore, the device is not acting like a TMD and any reduction in response is due to the coupling of the two buildings with a viscous damping device. It is also interesting to note that unlike the cost function which increases after the global minima, the pounding distance decreases with increasing frequency ratio.

\subsection{Equivalence of STMD and Viscous Coupling of the Two Buildings}

Based on the discussion above, it is apparent that a very stiff TMD is equivalent, in terms of structural response reduction, to a viscous dashpot coupling the two buildings. To illustrate this point better, we modify the system shown in Figure 1 by lumping the TMD mass on building A, and connecting the two buildings by the same viscous dashpot as that used in the STMD. The resulting system has only two degrees of freedom with masses $\left(m_{\mathrm{a}}+m\right)$ and $m_{\mathrm{b}}$ connected by a dashpot $c$. The mass $\left(m_{\mathrm{a}}+m\right)$ is connected to the ground by spring and dashpot $k_{\mathrm{a}}$ and $c_{\mathrm{a}}$, while $m_{\mathrm{b}}$ is connected to the ground by spring and dashpot $k_{\mathrm{b}}$ and $c_{\mathrm{b}}$. The peak response of this modified system is divided by the peak response of the system with STMD. The ratio of peak displacement of building A is presented, for the El Centro ground motion, as a function of frequency ratio and damping ratio in Figure 4. When the shared TMD is near resonance with building A, it is more effective than viscous coupling alone. However, as the frequency ratio is increased, the two systems approach each other, and for a frequency ratio greater than about 20, there is no difference between the two systems. This helps us conclude that STMD optimized on the global minima of the cost function is not a tuned mass damper, as the mass is neither tuned to the structure, nor does it play any part in reducing structural response. In this sense, it is illogical to use additional TMD mass and a very stiff spring element, when the same effect can be obtained by just connecting the two buildings with a viscous dashpot.

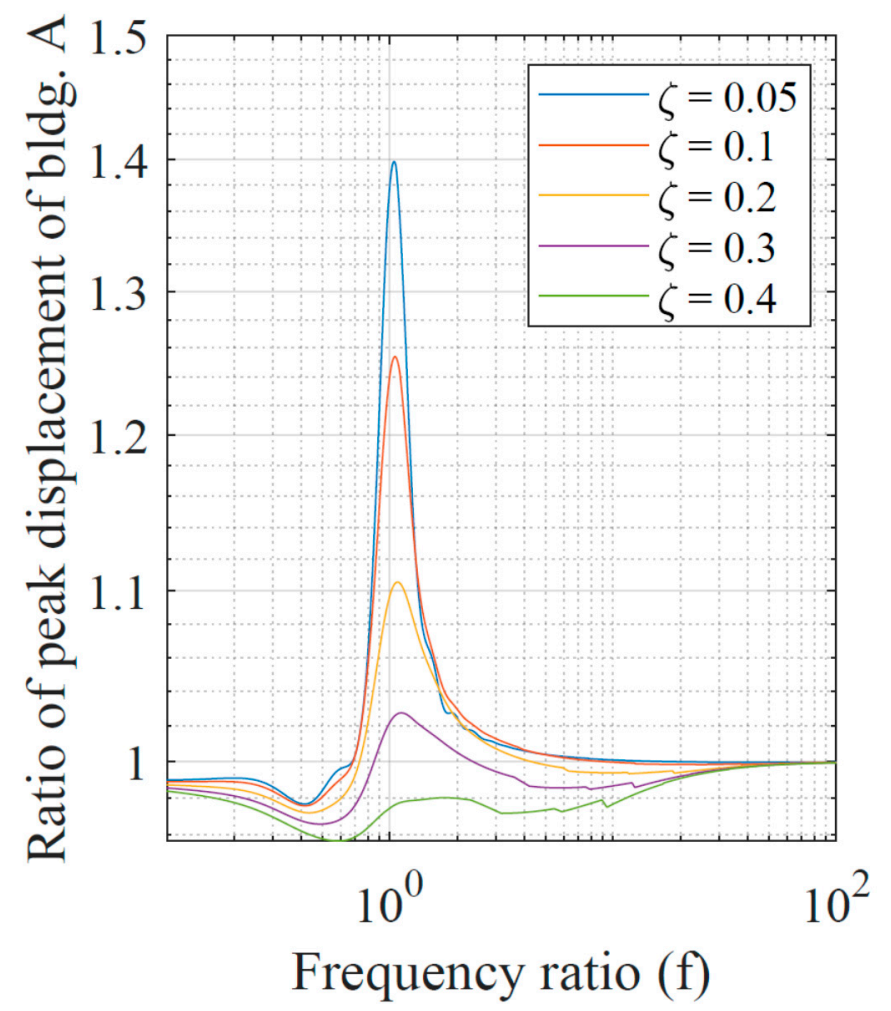

Figure 4. The ratio of maximum displacement of building A when the two buildings are connected by a viscous dashpot and an STMD. 


\subsection{Examination with MDOF Systems}

Here we examine the results and conclusions obtained for two SDOF buildings with MDOF models of two buildings. The selected buildings are the same as those used by Abdullah et al. [28]. Building A has a mass of $3.1752 \times 10^{5} \mathrm{~kg}$, and stiffness of $3.404 \times 10^{8} \mathrm{~N} / \mathrm{m}$ on each floor. Building B has a mass of $3.6287 \times 10^{5} \mathrm{~kg}$ and stiffness of $6.127 \times 10^{8}$ on each floor. Both buildings have 8 floors with a damping coefficient of $100 \mathrm{Ns} / \mathrm{m}$ on each floor. Fundamental frequencies of buildings $\mathrm{A}$ and $\mathrm{B}$ are 6.04, and $7.58 \mathrm{rad} / \mathrm{s}$, respectively. The mass of the TMD is $54,430 \mathrm{~kg}$. Abdullah et al. [28] present two cases as optimal solutions. Case 1 corresponds to attaching the TMD mass to building A by a dashpot and building B by a spring. Case 2 corresponds to a spring connection with building $\mathrm{A}$ and dashpot connection to building B. Case 2 was found to be more effective and is considered here for further analysis. Abdullah et al. [28] arrived at this solution by specifying weights equal to 1 for the displacements in the top four floors of building $\mathrm{A}$ and 0 for all other displacements and velocities in defining the $\mathbf{Q}$ matrix

The cost function for this example is presented in Figure 5. The frequency ratio, for this system, is defined as the frequency of the STMD divided by the fundamental frequency of building A. Like the cost function for SDOF buildings shown in Figure 2, the cost function of these MDOF buildings sharing a TMD displays two minima for each damping ratio. The first minima, which is larger than the second one, occurs near the resonance of STMD mass with the first mode of building A. The second minimum occurs at a much larger frequency ratio. The optimal stiffness presented by Abdullah et al. (2001) is $1.786 \times 10^{8} \mathrm{~N} / \mathrm{m}$, which is about $50 \%$ of the stiffness of each of the floors of building A. Based on this stiffness, the frequency of STMD is $57.28 \mathrm{rad} / \mathrm{s}$, which corresponds to a frequency ratio of 9.48 . The optimal damping coefficient reported by Abdullah et al. [28] is 1.809E6, which, for this frequency ratio corresponds to a damping ratio of 0.29 for the STMD. It is then clear that the optimal solution reported in Abdullah et al. [28] corresponds to the global minima of the cost function (see purple line in Figure 4).

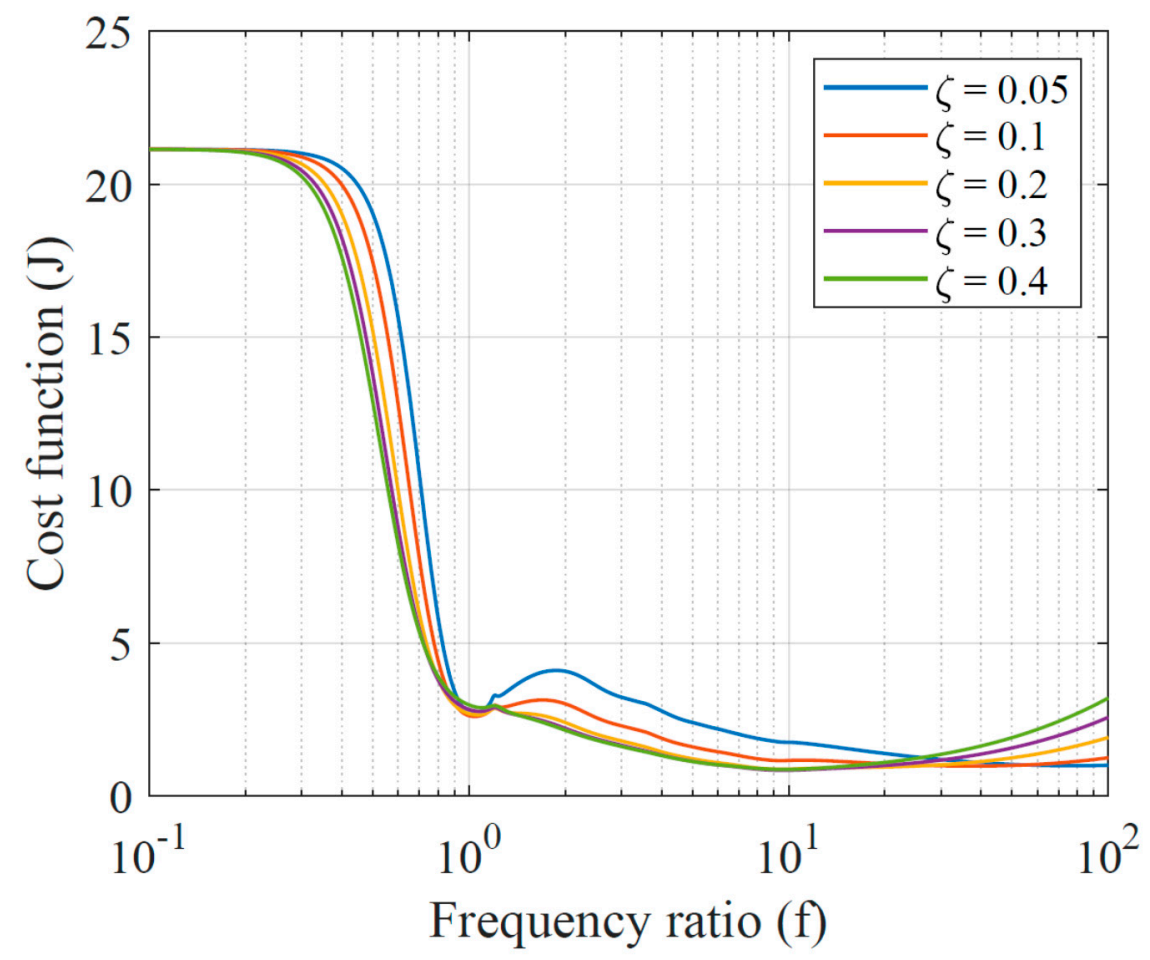

Figure 5. The cost function for the two eight-storey buildings presented in Abdullah et al. [28] as a function of frequency and damping ratios. 
Variation of the peak displacements of buildings A and B with frequency ratio and damping ratio is shown in Figure 6. The solution considered optimal by Abdullah et al. [28] is indicated in the figure with red dots. The response of building A, to which the STMD mass is connected by a spring, is optimally controlled when the frequency ratio is close to 1 , and the damping ratio is low. This solution, however, is not effective in controlling the response of building B. The optimal solution, based on the global minima of $J$, as denoted by red dots, is effective in controlling pounding as well as reducing the response of both the buildings. However, the solution uses a very stiff spring, and the TMD mass does not move relative to building $\mathrm{A}$.
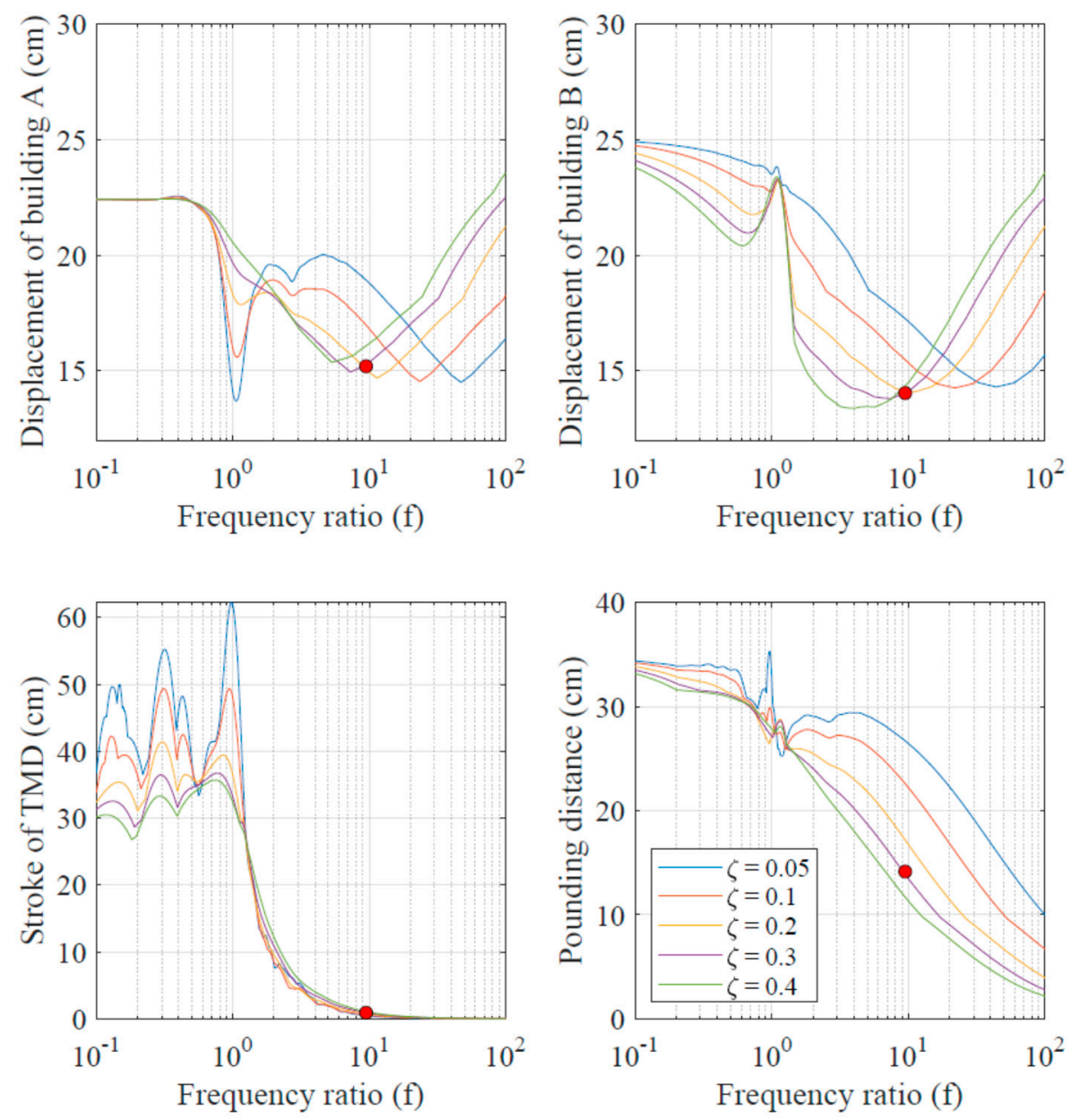

Figure 6. Peak roof displacements, device stroke, and the minimum separation distance between two buildings connected by an STMD. The optimal solution presented in Abdullah [28] is shown with red dots. The results correspond to El Centro ground motion.

This can be confirmed from the low stroke of the device as shown in Figure 6. The STMD mass, in the solution presented by Abdullah et al. [28] is essentially motionless and does not function as intended. The solution, therefore, is not a tuned mass damper as its frequency is much larger than the frequency of the buildings it is attached to. In fact, it can be verified that the same response reduction can be achieved by coupling the two buildings with a dashpot. If we consider the optimal solution as the one near resonance of STMD with building A, the STMD is not very effective in controlling pounding between the buildings.

\subsection{Effectiveness of STMDs}

Based on the results and arguments presented above, the stiff solution cannot be considered as a shared TMD. However, we can define a shared TMD in such a way that it is tuned to the frequency 
of building A, for example. This solution would correspond to the frequency ratio in the vicinity of 1. An optimal STMD in this context would correspond to the one that minimizes the cost function $J$ in the vicinity of resonance with building A. The example presented above shows that this STMD marginally reduces the pounding distance for the El Centro ground motion. To test if this observation can be generalized to different ground motions and quantify the effectiveness in reducing pounding distance, we use several ground motion records for dynamic analysis of the system. The ground motion records are taken from the European Strong Motion Database [31]. The database contains 462 ground motion records from 110 earthquakes recorded in Europe and the Middle East. The ground motions are obtained from earthquakes with a moment magnitude of 4.2 to 7.6. The range of epicentral distance is 1 to $558 \mathrm{~km}$, and that of peak ground acceleration (PGA) is $0.9 \%$ to $91 \%$ of acceleration due to gravity. The strong motion duration, defined as the interval covering $5-95 \%$ of Arias Intensity is in the range of $1.2 \mathrm{~s}$ to $139 \mathrm{~s}$. Response spectra and duration of these ground motions have been presented in Rupakhety and Sigbjörnsson [32,33]. More details about this database can be found in Ambraseys et al. [34].

Optimal parameters of the STMD are estimated by minimizing the cost function using a genetic algorithm. Population size is taken as 50 and the initial population follows uniform distribution in the specified bounds. Elite count is set to $5 \%$ of the population. Crossover fraction is set to 0.8 and migration fraction is set to 0.2 . The selection criterion is stochastic uniform and mutation are Gaussian. The 'ga' function in Matlab ${ }^{\mathrm{TM}}$ with default options was used to implement the algorithm. Different scenarios are simulated: (i) both the buildings are uncontrolled; (ii) TMD is used in building A only, the parameters of the TMD are optimized based on Sadek's (1997) equations; (iii) the STMD is connected with a spring to building A, and a dashpot to building B. These cases are denoted hereafter as UC (uncontrolled), AC (building A controlled), and SC (controlled with STMD), respectively. In all cases, the TMD mass is taken as $1 \%$ of the mass of building A.

Peak roof displacement of building A and pounding distance corresponding to the 462 earthquake ground motions are presented in Figure 7. The response of the uncontrolled and controlled structures are plotted on the abscissa and ordinate, respectively. The diagonal lines in the figure correspond to the equal response of uncontrolled and controlled structures. The results show that the TMDs result in reduction of peak roof displacement of building A in almost all the ground motions. When the displacement of the uncontrolled structure is small, the response reduction obtained by the TMD is not very significant. However, as the ground motions get more demanding, the effectiveness of the TMDs is higher. For the most severe case (that producing the highest response of the uncontrolled structure), the TMD reduces the response by about $50 \%$. However, it is interesting to note that when the TMD is shared with building B, its effectiveness in controlling the response of building A remains almost unchanged for all the ground motions considered in this study. This shows that sharing the TMD with building B does not reduce its effectiveness. The shared TMD is not effective in controlling the response of building B. Neither does it provide any advantage in reducing the pounding distance between the two buildings. The optimal STMD, therefore, does not provide any clear advantage over the TMD installed on building A alone.

The mean (over 462 ground motions) ratios between the pounding distance of the AC controlled and SC controlled structures to that of the uncontrolled structure are 0.79 and 0.76 , respectively. Controlling building A alone is, on average, about $3 \%$ less effective than using an STMD. The stiffnesses of AC and SC schemes are $8.96 \times 10^{5} \mathrm{~N} / \mathrm{m}$ and $9.68 \times 10^{5} \mathrm{~N} / \mathrm{m}$, respectively. Their damping coefficients are $4.73 \times 10^{4} \mathrm{~kg} / \mathrm{s}$ and $2.27 \times 10^{4} \mathrm{~kg} / \mathrm{s}$. This shows that the SC scheme results in similar performance like the AC scheme, but with a much smaller dashpot. This might be, in theory, an advantage of sharing the device. However, there might be practical difficulties in properly connecting the dashpot between the two buildings, and suitability of the scheme needs to be judged on a case by case basis. 

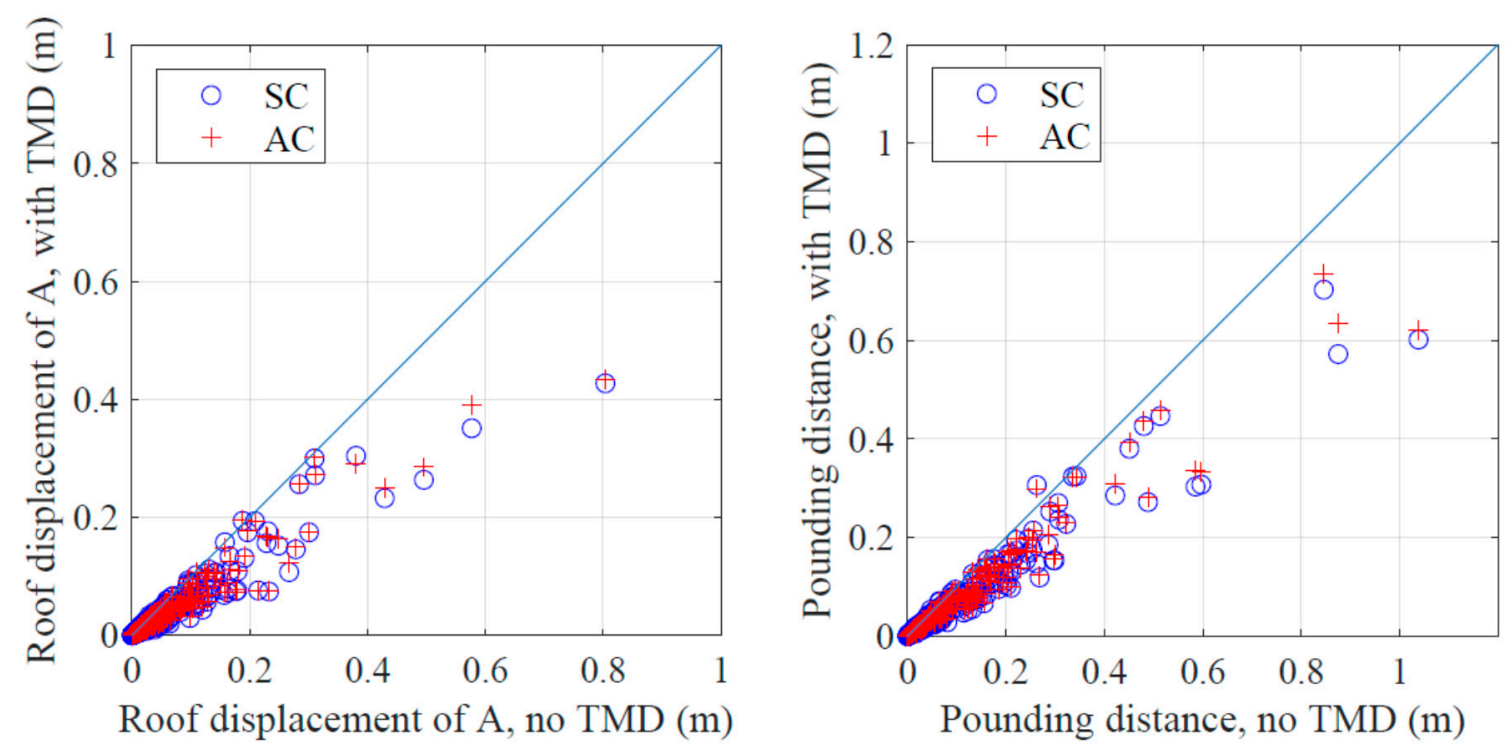

Figure 7. Roof displacement of building A (left) and minimum separation distance to avoid pounding (right) when subjected to 462 earthquake ground motions. The abscissa and ordinate correspond to uncontrolled and controlled structures, respectively.

To illustrate the effectiveness of AC and SC schemes in reducing the minimum separation distance between the two buildings, reduction ratio, which is defined as minimum separation distance of the controlled building divided by that of the uncontrolled building is shown in Figure 8. The smaller this ratio, the more effective is the control scheme. Effectiveness is investigated against different ground motion and structural response parameters. Only those ground motions with PGA larger than $0.2 \mathrm{~g}$ are used in the figure. Here, g represents acceleration due to gravity. Ground motions weaker than this are not considered as they were found to cause a low risk of pounding. Figure $8 \mathrm{c}$ shows two different clusters of data, one below $\sim 25 \mathrm{~s}$, and the other to its right. The cluster to the right has very few data points, and any apparent trend in this cluster is not reliable. When duration is less than $25 \mathrm{~s}$, the Pearson correlation coefficient between reduction ratio and duration is -0.44 with a p-value of 0.0011 , which shows that the correlation is statistically significant, and not by random chance. Figure $8 \mathrm{~b}$ shows that the effectiveness of the TMDs is independent of PGA. There seems to be a weak negative correlation between the pounding distance of the uncontrolled structure and the effectiveness of TMD schemes. The Pearson correlation coefficient was found to be -0.17 with a large p-value of 0.21 , which means that any apparent trend in the data is statistically insignificant. The same observation can be made in Figure 8d, which shows that the effectiveness of TMD schemes is independent of spectral displacement at the fundamental period of the uncontrolled structure. In all these cases, there is no significant difference between the SC and AC schemes, which means that sharing the TMD does not seem to provide additional benefit in preventing pounding.

We next compare the effectiveness of the SC scheme to that of the AC scheme for different mass ratios of the TMD. Mass of the TMD is taken as 1\%, $2 \%$, and 3\% of the total mass of building A. The optimal solutions for these mass ratios were found with frequency ratios of 1.02, 1.04, and 1.04 and damping ratios of $7 \%, 11 \%$, and $13 \%$. The effectiveness of the devices is quantified by the mean ratios of pounding distance of SC and AC schemes to that of uncontrolled structure, denoted by $r_{S C}$ and $r_{A C}$ respectively. A value of this ratio less than 1 means the control systems, on average, reduce pounding distance. These ratios are shown in Figure 9. As the mass ratio increases, the performance of SC is better than that of AC. However, even for a mass ratio of $3 \%$, which corresponds to $24 \%$ of floor mass, the SC scheme is only about $6 \%$ better than the AC scheme. We repeated the analysis with different frequencies of the two buildings and arrived at similar results. 


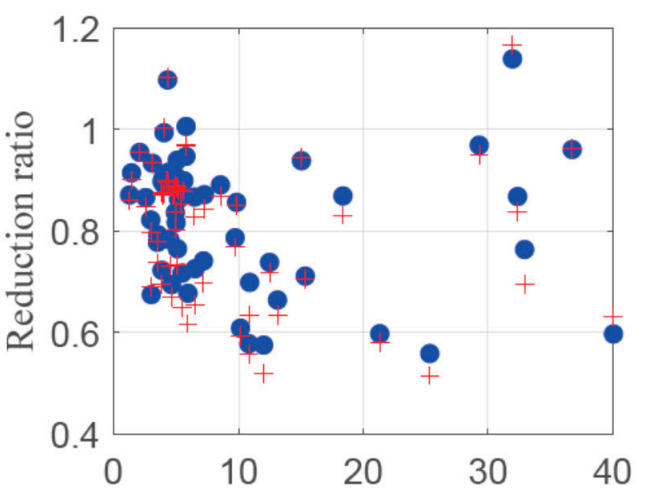

(a) Duration (s)

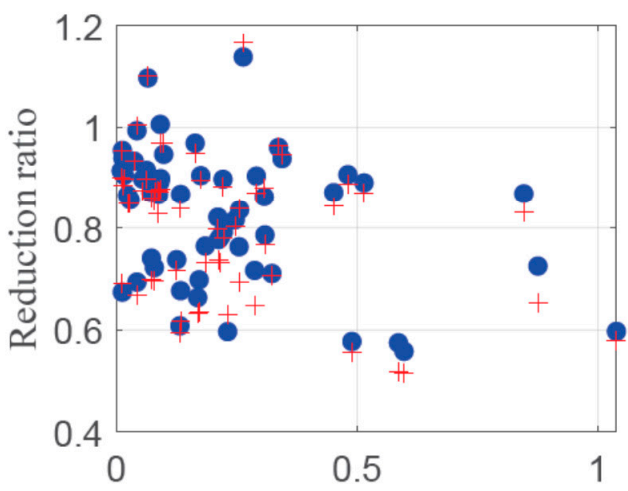

(c) Pounding distance uncontrolled (m)

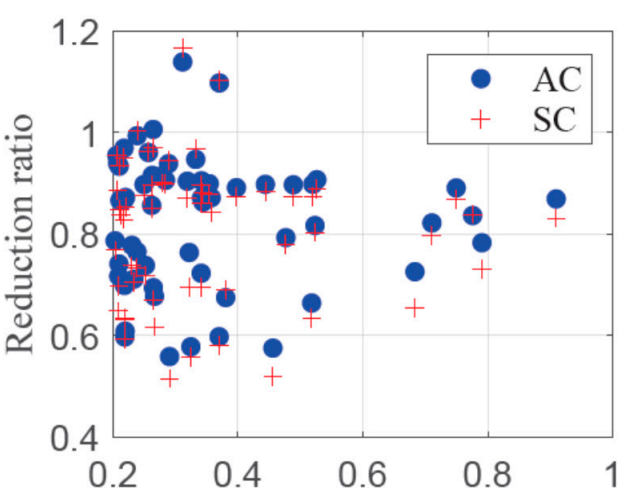

(b) PGA (g)

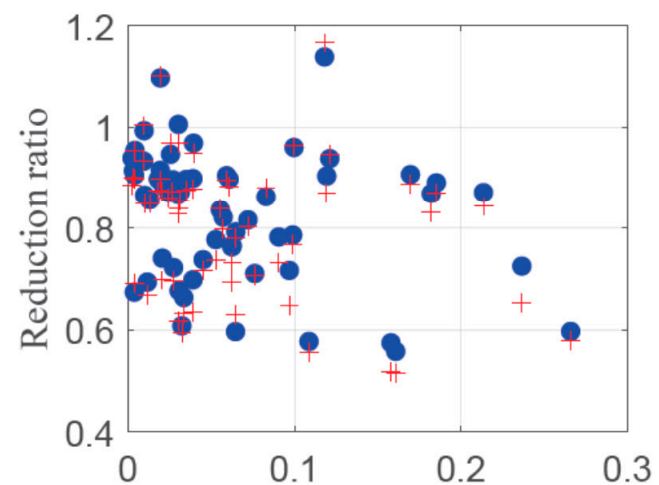

(d) Spectral displacement at $\mathrm{T}_{1}(\mathrm{~m})$

Figure 8. Effectiveness of tuned mass dampers in reducing the minimum separation distance to prevent pounding. The variation of effectiveness with different ground motion parameters is presented for those ground motion whose PGA is larger than $20 \%$ of acceleration due to gravity.

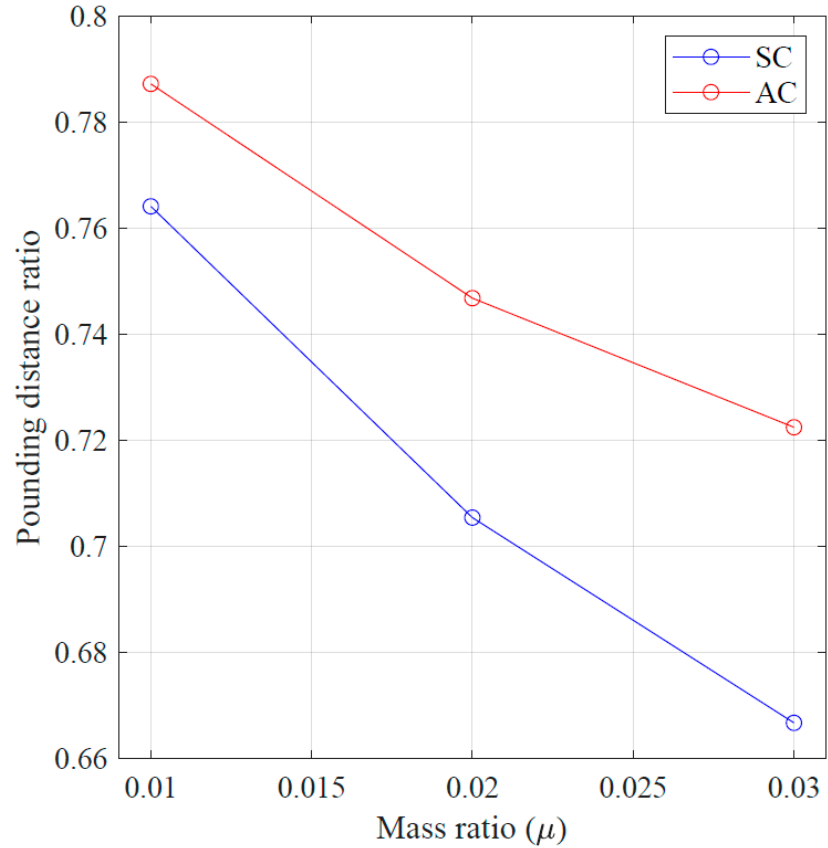

Figure 9. Ratio of pounding distance of the two buildings with controlled with STMD (SC) and building A controlled (AC) schemes to that of uncontrolled buildings. 


\section{Conclusions}

This study revisits the idea of shared TMD for mitigation of seismic pounding between adjacent buildings. Dynamics of an optimal solution reported to be effective in Abdullah et al. [28] is investigated in detail to arrive at the following conclusions.

1. The solution proposed in the literature does not act like a tuned mass damper. The mass of the device is not tuned to the structure it is connected to; it is very stiff and as a result, the device does not move. Any reduction in response resulting from such devices is due to the viscous coupling of the two buildings rather than the tuned vibration of the STMD mass. Our results show that a similar level of effectiveness can be achieved without the TMD mass, simply by coupling the two buildings by a viscous dashpot. This eliminates the need for extra costs required to support the additional mass of the TMD.

2. The cost function for optimization of STMDs displays two minima, one near resonance of the device with one of the buildings, and the other at a frequency much larger than that of the buildings. The solution near the resonance is a tuned mass damper, while the other one is equivalent to the viscous coupling of two buildings.

3. For a large set of 462 ground motions, an optimal TMD placed on one of the buildings alone was found to be almost as effective as an STMD tuned to the building both in controlling roof displacement of the building and pounding distance with an adjacent building. The trouble of sharing the TMD with another building is therefore not worthwhile.

Author Contributions: All authors discussed and agreed upon the idea, and made scientific contributions. All authors have read and agreed to the published version of the manuscript.

Funding: This research was funded by University of Iceland Research Fund.

Acknowledgments: We acknowledge constructive and insightful comments and discussions from two anonymous reviewers and the editors, which helped improve the paper. The authors acknowledge support from the University of Iceland Research Fund.

Conflicts of Interest: The authors declare no conflict of interest.

\section{References}

1. Abdel Raheem, S.E. Mitigation measures for earthquake induced pounding effects on seismic performance of adjacent buildings. Bull. Earthq. Eng. 2014, 12, 1705-1724. [CrossRef]

2. Miari, M.; Choong, K.K.; Jankowski, R. Seismic pounding between adjacent buildings: Identification of parameters, soil interaction issues and mitigation measures. Soil Dyn. Earthq. Eng. 2019, 121, 135-150. [CrossRef]

3. Abdel Raheem, S.E.; Fooly, M.Y.; Shafy, A.G.; Taha, A.M.; Abbas, Y.A.; Latif, M.M. Numerical simulation of potential seismic pounding among adjacent buildings in series. Bull. Earthq. Eng. 2019, 17, 439-471. [CrossRef]

4. Dimitrakopoulos, E.; Makris, N.; Kappos, A.J. Dimensional analysis of the earthquake-induced pounding between adjacent structures. Earthq. Eng. Struct. Dyn. 2009, 38, 867-886. [CrossRef]

5. Anagnostopoulos, S.A.; Karamaneas, C.E. Use of collision shear walls to minimize seismic separation and to protect adjacent buildings from collapse due to earthquake-induced pounding. Earthq. Eng. Struct. Dyn. 2008, 37, 1371-1388. [CrossRef]

6. Dicleli, M. Performance of seismic-isolated bridges with and without elastic-gap devices in near-fault zones. Earthq. Eng. Struct. Dyn. 2008, 37, 935-954. [CrossRef]

7. Jankowski, R.; Mahmoud, S. Linking of adjacent three-storey buildings for mitigation of structural pounding during earthquakes. Bull. Earthq. Eng. 2016, 14, 3075-3097. [CrossRef]

8. Richardson, A.; Walsh, K.K.; Abdullah, M.M. Closed-form equations for coupling linear structures using stiffness and damping elements. Struct. Control Health Monit. 2013, 20, 259-281. [CrossRef]

9. Richardson, A.; Walsh, K.K.; Abdullah, M.M. Closed-form design equations for controlling vibrations in connected structures. J. Earthq. Eng. 2013, 17, 699-719. [CrossRef]

10. Patel, C.C.; Jangid, R.S. Seismic response of dynamically similar adjacent structures connected with viscous dampers. IES J. Part A Civ. Struct. Eng. 2010, 3, 1-3. [CrossRef] 
11. Patel, C.C.; Jangid, R.S. Dynamic response of identical adjacent structures connected by viscous damper. Struct. Control Health Monit. 2014, 21, 205-224. [CrossRef]

12. Tubaldi, E.; Barbato, M.; Ghazizadeh, S. A probabilistic performance-based risk assessment approach for seismic pounding with efficient application to linear systems. Struct. Saf. 2012, 36, 14-22. [CrossRef]

13. Pratesi, F.; Sorace, S.; Terenzi, G. Analysis and mitigation of seismic pounding of a slender R/C bell tower. Eng. Struct. 2014, 71, 23-34. [CrossRef]

14. Sorace, S.; Terenzi, G. Damped interconnection-based mitigation of seismic pounding between adjacent R/C buildings. Int. J. Eng. Technol. 2013, 5, 406. [CrossRef]

15. Abdeddaim, M.; Ounis, A.; Djedoui, N.; Shrimali, M. Reduction of pounding between buildings using fuzzy controller. Asian J. Civ. Eng. 2016, 17, 985-1005.

16. Uz, M.E.; Hadi, M.N. Optimal design of semi active control for adjacent buildings connected by MR damper based on integrated fuzzy logic and multi-objective genetic algorithm. Eng. Struct. 2014, 69, 135-148. [CrossRef]

17. Cao, L.; Li, C. Tuned tandem mass dampers-Inerters with broadband high effectiveness for structures under white noise base excitations. Struct. Control Health Monit. 2019, 26, e2319. [CrossRef]

18. Elias, S.; Matsagar, V. Research developments in vibration control of structures using passive tuned mass dampers. Annu. Rev. Control 2017, 44, 129-156. [CrossRef]

19. Anagnostopoulos, S.A.; Spiliopoulos, K.V. An investigation of earthquake induced pounding between adjacent buildings. Earthq. Eng. Struct. Dyn. 1992, 21, 289-302. [CrossRef]

20. De Domenico, D.; Ricciardi, G. Earthquake-resilient design of base isolated buildings with TMD at basement: Application to a case study. Soil Dyn. Earthq. Eng. 2018, 113, 503-521. [CrossRef]

21. Stanikzai, M.H.; Elias, S.; Matsagar, V.A.; Jain, A.K. Seismic response control of base-isolated buildings using tuned mass damper. Aust. J. Struct. Eng. 2019, 1-2. [CrossRef]

22. Stanikzai, M.H.; Elias, S.; Matsagar, V.A.; Jain, A.K. Seismic Response Control of Base-Isolated Buildings Using Multiple Tuned Mass Dampers. Struct. Des. Tall Spec. Build 2019, 28, e1576. [CrossRef]

23. Stanikzai, M.H.; Elias, S.; Rupakhety, R. Seismic Response Mitigation of Base-Isolated Buildings. Appl. Sci. 2020, 10, 1230. [CrossRef]

24. De Domenico, D.; Ricciardi, G. An enhanced base isolation system equipped with optimal tuned mass damper inerter (TMDI). Earthq. Eng. Struct. Dyn. 2018, 47, 1169-1192. [CrossRef]

25. Hashimoto, T.; Fujita, K.; Tsuji, M.; Takewaki, I. Innovative base-isolated building with large mass-ratio TMD at basement for greater earthquake resilience. Future Cities Environ. 2015, 1, 9. [CrossRef]

26. De Domenico, D.; Ricciardi, G.; Zhang, R. Optimal design and seismic performance of tuned fluid inerter applied to structures with friction pendulum isolators. Soil Dyn. Earthq. Eng. 2020, 132, 106099. [CrossRef]

27. De Domenico, D.; Gandelli, E.; Quaglini, V. Effective base isolation combining low-friction curved surface sliders and hysteretic gap dampers. Soil Dyn. Earthq. Eng. 2020, 130, 105989. [CrossRef]

28. Abdullah, M.M.; Hanif, J.H.; Richardson, A.; Sobanjo, J. Use of a shared tuned mass damper (STMD) to reduce vibration and pounding in adjacent structures. Earthq. Eng. Struct. Dyn. 2001, 30, 1185-1201. [CrossRef]

29. Kim, H.S. Seismic response control of adjacent buildings coupled by semi-active shared TMD. Int. J. Steel Struct. 2016, 16, 647-656. [CrossRef]

30. Sadek, F.; Mohraz, B.; Taylor, A.W.; Chung, R.M. A method of estimating the parameters of tuned mass dampers for seismic applications. Earthq. Eng. Struct. Dyn. 1997, 26, 617-635. [CrossRef]

31. Ambraseys, N.N.; Smit, P.; Douglas, J.; Margaris, B.; Sigbjörnsson, R.; Olafsson, S.; Suhadolc, P.; Costa, G. Internet site for European strong-motion data. Boll. Di Geofis. Teor. Ed Appl. 2004, 45, 113-129.

32. Rupakhety, R.; Sigbjörnsson, R. Rotation-invariant measures of earthquake response spectra. Bull. Earthq. Eng. 2013, 11, 1885-1893. [CrossRef]

33. Rupakhety, R.; Sigbjörnsson, R. Rotation-invariant mean duration of strong ground motion. Bull. Earthq. Eng. 2014, 12, 573-584. [CrossRef]

34. Ambraseys, N.N.; Douglas, J.; Sigbjörnsson, R.; Berge-Thierry, C.; Suhadolc, P.; Costa, G.; Smit, P.M. Dissemination of European strong-motion data, Volume 2. In Proceedings of the 13th World Conference on Earthquake Engineering, Vancouver, CO, Canada, 1-6 August 2004.

(C) 2020 by the authors. Licensee MDPI, Basel, Switzerland. This article is an open access article distributed under the terms and conditions of the Creative Commons Attribution (CC BY) license (http://creativecommons.org/licenses/by/4.0/). 